\title{
Influence of duration of symptoms over perioperative outcomes during emergency laparoscopic cholecystectomy
}

\author{
Sharma SK ${ }^{1}$, Thapa PB ${ }^{2}$, Maharjan DK ${ }^{3}$, Dhakal A $\mathbf{A}^{4}$, Baral $\mathbf{N}^{4}$ \\ ${ }^{1}$ Associate Professor, ${ }^{2}$ Assistant Professor, ${ }^{3}$ Lecturer, ${ }^{4}$ Intern, Department of Gastrointestinal and Endoscopic Surgery, \\ Department of General Surgery, Kathmandu Medical College, Sinamangal, Nepal
}

\begin{abstract}
Background: Laparoscopic cholecystectomy is a gold standard treatment for gall stone diseases. Early surgical intervention in acute calculus cholecystitis is feasible and duration of onset of symptoms does not influence the conversion rate.

Objective: To compare the safety and feasibility between urgent and delayed laparoscopic cholecystectomy in patients with acute calculus cholecystitis.

Materials and methods: This is a comparative study conducted in Department of Surgery, Kathmandu Medical College, during the period of January 2006 to January 2008. Alltogether, 436 patients were analysed out of which 55 were selected as urgent laparoscopic cholecystectomy and were included in the study. Among 55 patients presented with acute calculus cholecystitis were divided into two groups. Group 1 underwent laparoscopic cholecystectomy within 72 hours of onset of pain abdomen and Group 2 after 72 hours of onset of pain abdomen.

Results: Conversion rate in Group 1 was $19.44 \%$ whereas it was $263 \%$ in Group $2(p=.693)$. There was no statistically significant difference in mean operating time $(\mathrm{p}=.412)$, total hospital stay $(\mathrm{p}=.626)$, bile duct injury and postoperative complications.
\end{abstract}

Conclusion: Urgent laparoscopic cholecystectomy is safe and duration of onset of pain abdomen does not influence conversion rate.

Key words: Urgent laparoscopic cholecystectomy, Conversion rate, acute calculus cholecystitis

Dlective laparoscopic cholecystectomy has Cbeen established as gold standard method for symptomatic gall stone disease ${ }^{1}$. With emerging concept of day care surgery and age of cutting costs, it has lead to numerous questions whether the use of laparoscopic cholecystectomy as emergency reduces hospital costs, procedural and patient complications, operative timing, conversion to open cholecystectomy and duration of hospital stay. During its initial period, skeptical reports were published regarding use of laparoscopic cholecystectomy during acute cholecystitis reporting more conversion rate, longer hospital stay and more complications ${ }^{2,3}$ but with increasing experience, reports are in favour of early laparoscopic cholecystectomy in acute cholecystitis ${ }^{4,5}$. Hence timing of surgery was divided into early surgery (referring to operation within 72 hours of hospital admission) and delayed surgery (referring to supportive care only during initial presentation followed by discharge upon resolution of symptoms and readmission 6-12 weeks later for a laparoscopic cholecystectomy). However, very few studies have incorporated laparoscopic cholecystectomy along with duration of onset of pain abdomen to surgical outcomes like conversion rate r,7 $^{6,}$
The aim of this study was to compare the safety and feasibility of emergency laparoscopic cholecystectomy (within 72 hours of pain abdomen) with delayed laparoscopic cholecystectomy (after 72 hours) in patient with acute cholecystitis.

\section{Materials and methods}

This study was conducted in Department of Surgery in Kathmandu Medical College Teaching hospital, which is 700 bedded hospital with surgical occupancy of 100 beds with surgical intensive care unit (ICU) and high dependency unit (HDU) facilities. From Jan 2006-Jan 2008, 436 patients underwent laparoscopic cholecystectomy. During this period, 55 patients had acute cholecystitis who was admitted through emergency department with diagnosis made based under following criteria:

- $\quad$ acute pain over right upper quadrant

\section{Correspondence}

Dr. Sunil Kumar Sharma

Department of General Surgery,

Kathmandu Medical College Teaching Hospital,

Sinamangal, Kathmandu, Nepal

E-mail: samknp@yahoo.com 
- $\quad$ fever $>37.8^{\circ} \mathrm{C}$

- leucocytosis $>11,000 / \mathrm{cu} \mathrm{mm}$

- clinical Murphy's sign positive

- Ultrasonic evidence of acute cholecystitis(presence of gall stones, ultrasound Murphy's sign, pericholecystic fluid collection):

All preoperative, intraoperative and postoperative data was collected through pre-designed proforma.

The patients with acute cholecystitis were divided into two groups:

- Those undergoing laparoscopic cholecystectomy within 72 hours of pain abdomen.

- Those undergoing after 72 hours of pain abdomen for acute cholecystitis.

The relationship between duration of symptoms and conversion (laparoscopic to open), operating time and length of hospital were assessed.

Data were analyzed using software package SPSS version 14. Statistical analysis was performed by the Mann-Whitney U-test and proportion test as applicable. $\mathrm{P}$ value less than 0.05 was taken as statistically significant.

\section{Result}

A total of 435 patients underwent laparoscopic cholecystectomy. Among them 343 were female and 93 were male. Among which 55 had undergone laparoscopic cholecystectomy for acute calculus cholecystitis. Among them, six patients had per-operative dilated common bile duct which was missed in ultrasound, three had undergone laparoscopic common bile duct exploration, while two had laparoscopic cholecystectomy followed by ERCP and one patient was converted due to Mirrizi's type III. Five patients with biliary pancreatitis underwent laparoscopic cholecystectomy after six weeks.

Among 55 patients who presented with acute calculus cholecystitis were divided into two groups. Group 1 was patient with acute calculus cholecystitis who underwent laparoscopic cholecystectomy within 72 hours of onset of pain abdomen and group 2 who underwent surgery after 72 hours of pain abdomen.

Estimated blood loss was minimal and none of the patient had bile duct injury. However two patients in group 1 and one patient in group 2 had post operative local wound complications after conversion. There was no difference between groups in the operating time or total hospital stay (Table 1). Table 2 shows the cause for conversion in converted cholecystectomies.

Table 1: Difference between two groups of patient group I ( $<72$ hours) and group II ( $>72$ hours)

\begin{tabular}{|l|c|c|c|}
\hline \multirow{2}{*}{} & \multicolumn{3}{|c|}{ Duration of pain abdomen } \\
\cline { 2 - 4 } & $<\mathbf{7 2}$ hours & $>\mathbf{7 2}$ hours & P- value \\
\hline Number of patients & 36 & 19 & 0.350 \\
\hline Age & $\begin{array}{c}39 \text { years(median) } \\
\text { Range(15-72 years) }\end{array}$ & $\begin{array}{c}44 \text { years(median) } \\
\text { Range(20-63years })\end{array}$ & \\
\hline Sex & 36 female & 19 female & $0.693^{\alpha}$ \\
\hline Conversion rate & $7(19.44 \%)$ & $5(26.3 \%)$ & 0.412 \\
\hline Operating time(In minutes) & $\begin{array}{c}34 \text { minutes } \\
(20-76)\end{array}$ & $\begin{array}{c}34 \text { minutes } \\
(20-70)\end{array}$ & 0.626 \\
Median(range) & $\begin{array}{c}3 \text { days } \\
1-9 \text { days }\end{array}$ & $\begin{array}{c}4 \text { days } \\
2-11 \text { days }\end{array}$ & NS \\
\hline Total hospital duration (in days) & 0 & 0 & NS \\
Median (range) & 2 & 1 & \\
\hline Bile duct injury & \multicolumn{3}{|c|}{} \\
\hline Post operative complications & \multicolumn{2}{|c}{ - calculated as Proportion Test NS- not significant } \\
\hline P-value calculated Mann-Whitney test $;$
\end{tabular}

Table 2: Cause for conversion from laparoscopic to open cholecystectomy

\begin{tabular}{|l|c|c|}
\hline & Frequency & Percentage \\
\hline Adhesion with frozen Calot's triangle & 10 & $18.2 \%$ \\
\hline Mirrizzi type II with hidden cystic duct syndrome & 1 & $1.8 \%$ \\
\hline Unclear anatomy with low cystic duct insertion. & 1 & $1.8 \%$ \\
\hline
\end{tabular}




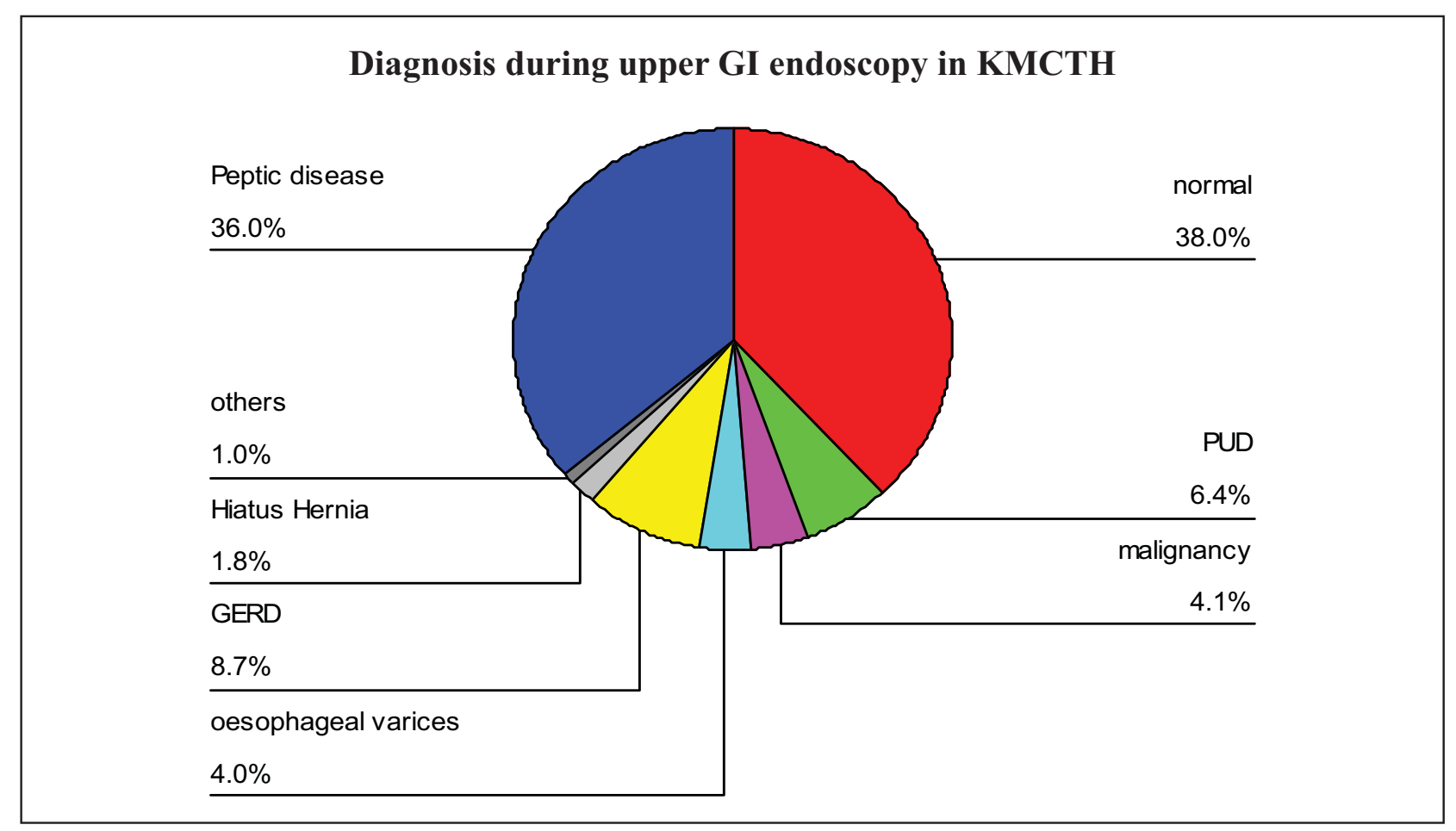

Fig 1: Prevalence of different disease during upper GI endoscopy.

\section{Discussion}

As emergency appendectomy is the standard treatment for acute appendicitis, no term has been coined as emergency laparoscopic cholecystectomy for acute calculus cholecystectomy. However terms like urgent laparoscopic cholecystectomy have been coined for operation to be done in index admission for acute calculus cholecystitis ${ }^{8}$. In Nepal when laparoscopic cholecystectomy gained its momentum from 1994 which was considered as gold standard for cholelithiasis, acute calculus cholecystitis used to be contraindication for laparoscopic approach ${ }^{9}$. With rapid achievement of learning curve and surgeons gaining more experience more acute cholecystitis are being dealt with laparoscopically though conversion rate were between $2-30 \%{ }^{10,11}$.

Regarding the timing of laparoscopic cholecystectomy in acute cholecystitis is still a controversy. Though early open cholecystectomy has no increased morbidity or mortality over delayed open cholecystectomy ${ }^{12}$ and delayed cholecystectomy increases the risks of further gallstone related complications ${ }^{13}$. There are concerns about higher morbidity rates in laparoscopic cholecystectomy performed as an emergency procedure ${ }^{14}$ and about the higher conversion rate to open procedure during the acute phase ${ }^{15}$. While one of the main reasons for conversion in early laparoscopic cholecystectomy is inflammation obscuring the view of Calot's triangle ${ }^{16}$, the main reason for conversion in the delayed group is fibrotic adhesions ${ }^{17}$. Severe inflammation is also one of the important reasons for bile duct injury ${ }^{18}$. There are also reports that the hospital stay is longer in early performed cholecystectomy ${ }^{19}$.

As said by John Hunter for treatment timing for acute cholecystitis as "get it while its hot" 20 , two prospective randomized trial have shown that early laparoscopic cholecystectomy for acute calculus cholecystitis has low morbidity, more cost effective and has lower overall conversion rate than delayed surgery(after 6 weeks of hospital admission ${ }^{21,22}$. Studies are focused with timing of surgery in terms of post admission status rather than duration of symptoms ${ }^{23}$. Study done by Hadad et $\mathrm{al}^{24}$ conclude that early intervention preferable within two days of onset of symptoms have less conversion rate than after two days. Similarly other studies have specified for intervention ranging from two days ${ }^{25}$, three days $^{26}$ to four days ${ }^{27}$ from onset of symptoms; however in our study duration of symptoms does not matter over conversion rate as conversion was necessary even with patient who presented with less than 72 hours.

In our study there was no statistical difference between conversion rate over laparoscopic cholecystectomy in less than 72 hours $(19.44 \%)$ and $>72$ hours $(26.3 \%)$ $(p=0.693)$. This is in agreement with a recent study that showed a delay in urgent surgery did not increase the conversion rate $^{28}$. In comparison ,Knight et $\mathrm{al}^{29}$ found 
conversion rate of 12 percent though other studies have reported rates of between 11 and 21 percent.

The rising conversion rate associated with delay in urgent cholecystectomy is related to a stage of acute inflammatory process. In an early phase, an oedematous plane exists between gall bladder and the liver bed letting dissection through gall bladder bed easier with less adhesion of omentum. However, once this phase have been settled, scarring and adhesion makes it difficult for dissection and moreover difficult gall bladder is problematic no matter when the surgery is performed.

Hence, along with duration of inflammation other factors are also responsible for conversion include old age, large stone, and non palpable gall bladder ${ }^{30}$.

In summary, emergency laparoscopic cholecystectomy for acute calculus cholecystitis is safe and associated with low conversion. Duration of onset of symptoms does not influence the conversion rate. However, randomized clinical trials are required to compare the conversion rate between emergency laparoscopic cholecystectomy and delayed surgery.

\section{References}

1. Soper NJ, Stockman PT, Dunnegan DL, Ashley SW. Laparoscopic Cholecystectomy: the new "gold standard"? Arch Surg. 1992; 127: 91723.

2. Cuscheiri A, Berci G, McSherry CK. Laparoscopic cholecystectomy. Am J Surg. 1990; 159:273.

3. Schirmer BD, Edge BS, Dix J, et al. Laparoscopic cholecystectomy: treatment of choice for symptomatic cholelithiasis. Ann Surg. 1991; 213:665-76

4. Lai PBS, Kwong KH, Leung KL. Randomized trial of early versus delayed laparoscopic cholecystectomy for acute cholecystitis. $\mathrm{Br} \mathrm{J}$ Surg .1998; 85(6):764-7.

5. Lo C, Liu C, Fan S, Lai ECS, Wong J. Prospective randomized study of early versus delayed laparoscopic cholecystectomy for acute cholecystitis. Ann Surg. 1998; 227(4):461-7.

6. Knight JS, Mercer SJ, Somers SS, Walters AM, Sadek SA, Toh SK. Timing of urgent laparoscopic cholecystectomy does not influence conversion rate. Br J Surg. 2004;91(5):601-4

7. Peng WK, Sheikh Z, Nixon SJ, Paterson-Brown S. Role of laparoscopic cholecystectomy in the early management of acute gallbladder disease. Br J Surg. 2005; 92(5):586-91.
8. Bhattacharya D, Senapati PS, Hurle R, Ammori BJ .Urgent versus interval laparoscopic cholecystectomy for acute cholecystitis: a comparative study. J Hepatobiliary Pancreat Surg. 2002; 9(5):538-42.

9. Shrestha S, Pradhan G, Bhoomi K, Dhital A , Bhattachan CL. Review of laparoscopic cholecystectomy in Nepal Medical College Teaching Hospital. Nepal Med Col J. 2007; 9(1):32-5.

10. Johansson M, Thune A, Nelvin L, Stiernstam M, Westman B, Lundell L. Randomized clinical trial of open versus laparoscopic cholecystectomy in the treatment of acute cholecystitis.. Br J Surg. 2005; 92(1):44-9.

11. Lai PB, Kwong KH, Leung KL, Kwok SP, Chan AC, Chung SC, Lau WY et al. Randomized trial of early versus delayed laparoscopic cholecystectomy for acute cholecystitis. $\mathrm{Br} \mathrm{J}$ Surg. 1998 ; 85(6):764-7.

12. Papi C, Catarci M, Ambrosio D, Gili L, Koch M, Grassi GB, et al. Timing of cholecystectomy for acute calculous cholecystitis: a meta-analysis. Am J Gastro 2004; 99(1):147-55.

13. Lawrentschuk N, Hewitt PM, Pritchard MG. Elective laparoscopic cholecystectomy: implications of prolonged waiting times for surgery. ANZ J Surg. 2003; 73(11):890-3.

14. Wilson P, Leese T, Morgan WP, Kelly JF, Brigg JK. Elective laparoscopic cholecystectomy for 'all-comers'. Lancet. 1991; 338(8770): 795-7.

15. Cuschieri A, Dubois F, Mouiel J, Mouret P, Becker H, Buess G, et al.The European experience with laparoscopic cholecystectomy. Am J Surg. 1991; 161(3):385-7.

16. Peng WK, Sheikh Z, Nixon SJ, Paterson-Brown $\mathrm{S}$. Role of laparoscopic cholecystectomy in the early management of acute gallbladder disease. Br J Surg. 2005;92:586-91.

17. .Lo CM, Liu CL, Lai EC, Fan ST, Wong J. Early versus delayed laparoscopic cholecystectomy for treatment of acute cholecystitis. Ann Surg. 1996; 223(1):37-42.

18. RichardsonMC, Bell G, Fullarton GM. Incidence and nature of bile duct injuries following laparoscopic cholecystectomy: an audit of 5913 cases. Br J Surg. 1996; 83(10):1356-60.

19. Lo CM, Liu CL, Lai EC, Fan ST, Wong J. Early versus delayed laparoscopic cholecystectomy for treatment of acute cholecystitis. Ann Surg. 1996; 223(1):37-42.

20. Hunter JG.Acute cholcecystitis revisited :get it while its hot. Ann Surg. 1998;227:468-9 
21. Lau H, Lo CY, Patil NG, Yuen WK. Early versus delayed-interval laparoscopic cholecystectomy for acute cholecystitis: a meta analysis. Surg Endo. 2006; 20(1):82-7.

22. Lo CM, Liu CL, Lai EC, Fan ST, Wong J. Early versus delayed laparoscopic cholecystectomy for treatment of acute cholecystitis. Ann Surg. 1996; 223(1):37-42.

23. Kolla SB, Aggarwal S, Kumar A, Kumar R, Chumber S, Parshad R, et al. Early vs delayed laparoscopic cholecystectomy for acute cholecystitis. Surg Endos. 2004; 18:1323-7.

24. Hadad SM, Vaidya JS, Baker L, Koh HC, Heron TP, Hussain K, Thompson AM. Delay from symptom onset increases the conversion rate in laparoscopic cholecystectomy for acute cholecystitis. World J Surg. 2008; 32(12):2747.

25. Madan AK, Aliabadi-Wahle S, Tesi D, Flint LM, Steinberg SM. How early is early laparoscopic treatment of acute cholecystitis? Am J Surg. 2002; 183(3):232-6.

26. Kitano S, Matsumoto T, Aramaki M, Kawano K. Laparoscopic cholecystectomy for acute cholecystitis. J Hepatobiliary Pancreat Surg. 2002; 9(5):534-7.
27. Uchiyama K, Onishi H, Tani M, Kinoshita H, Ueno M, Yamaue H. Timing of laparoscopic cholecystectomy for acute cholecystitis with cholecystolithiasis. Hepatogastroenterology. 2004; 51(56):346-8.

28. Bhattacharya D, Senapati PS, Hurle R, Ammori BJ. Urgent versus interval laparoscopic cholecystectomy for acute cholecystitis: a comparative study. J Hepatobiliary Pancreat Surg. 2002; 9(5):538-42.

29. Knight JS, Mercer SJ, Somers SS, Walters AM, Sadek SA, Toh SK. Timing of urgent laparoscopic cholecystectomy does not influence conversion rate. Br J Surg. 2004 ;91(5):601-4

30. Ibrahim S, Hean TK, Ho LS, Ravintharan T, Chye TN, Chee CH. Risk factors for conversion to open surgery in patients undergoing laparoscopic cholecystectomy. World J Surg. 2006; 30(9):1698-704. 